\title{
Improving the prevention of pressure ulcers as a way to reduce health care expenditures
}

\author{
Stacy Ackroyd-Stolarz PhD
}

$\mathrm{A}$ recent actuarial report stated that the Canadian health care system may not be sustainable in the absence of government action ${ }^{1}$ and recommended strategies such as placing substantial limits on health care spending. Adoption of all the recommendations is unlikely. However, one underrecognized opportunity for both reducing health care expenditures and improving patient care is better prevention of pressure ulcers. Although the prevention and care of pressure ulcers may have been viewed historically as a nursing care problem, it is a useful barometer of system-level quality and patient safety. ${ }^{2-4}$ Physicians across the continuum of care have a pivotal role to play in leading system change for the improvement of quality and safety.

To understand the potential for cost savings, it is important to appreciate how common and costly the problem of pressure ulcers is in Canada. The prevalence of pressure ulcers is estimated to be $25.1 \%$ (95\% confidence interval [CI] 23.8\%-26.3\%) in acute care settings, $29.9 \%$ (95\% CI $28.3 \%-31.4 \%$ ) in nonacute settings and $15.1 \%$ (95\% CI $13.4 \%-16.8 \%$ ) in community care settings. ${ }^{5}$ Although differences in study methodology make direct comparisons challenging, reported costs associated with pressure ulcers are consistently high. ${ }^{3,5-7}$ The annual cost of pressure ulcers is about $\$ 11$ billion in the United States ${ }^{6}$ and as much as $£ 2.1$ billion in the United Kingdom (about $4 \%$ of the entire National Health System budget). ${ }^{3}$ A five-year study involving older patients admitted to hospital in Ontario determined the adjusted net cost to be $\$ 44000$ and $\$ 90000$ for a hospital-acquired pressure ulcer at stage II and IV, respectively. ${ }^{8}$ The population at risk of pressure ulcers is expected to grow because of factors such as our aging population and increases in the incidence of impaired mobility and chronic conditions such as diabetes and obesity.,9 Accordingly, there is some urgency to establish effective strategies for the prevention of pressure ulcers. A coordinated approach appears to hold more promise for achieving cost savings than isolated changes or changes aimed exclusively at treatment. ${ }^{3,6}$
So where should we begin? More than half of pressure ulcers occur while patients are in hospital. ${ }^{3,6}$ These patients have longer lengths of stay and a higher risk of in-hospital mortality than inpatients in whom pressure ulcers have not developed. ${ }^{4,69}$ Prolonged hospital stays reduce the availability of acute care beds. In addition to experiencing pain and limitations in daily activities, a patient with a pressure ulcer may have to undergo additional procedures and receive more medications, intensive nursing or other specialized care. ${ }^{3,69}$ In a longitudinal study of mortality associated with pressure ulcers in the US, the age-adjusted mortality was 3.79 per 100000 population, and septicemia was reported in $39.7 \%$ of deaths. ${ }^{10}$ Early detection of pressure ulcers by physicians is important for the identification and management of patients at high risk of secondary complications such as osteomyelitis and sepsis. ${ }^{4}$

Not all pressure ulcers occur in hospital, nor can they all be prevented. ${ }^{3,6}$ However, primary prevention has the potential to save scarce resources and should begin among high-risk individuals in hospital, in a setting with established policies, structures and monitoring mechanisms, and may help to prevent the progression of early stage ulcers. ${ }^{3,6}$ It may also reduce the burden of care of discharged patients in the community.

Prevention strategies in acute care settings have been found to be effective. A 2013 systematic review identified moderately strong evidence that supports a multicomponent strategy for the prevention of pressure ulcers. The strategy involves the use of multidisciplinary teams, clinical- and system-level leadership, sustained

\section{- Ker pOINTS}

- Pressure ulcers are a common and costly problem across the health care continuum.

- Pressure ulcers may be an informative barometer of system-level quality of care and patient safety.

- Prevention of pressure ulcers is an underrecognized opportunity to reduce health care expenditures and to improve patient care.

- Physicians have a pivotal role to play in leading system change for improving quality of care and patient safety.
Competing interests: Stacy Ackroyd-Stolarz has received a grant from the Canadian Institutes of Health Research and salary support from the Capital

District Health Authority, Halifax, NS.

This article has been peer reviewed.

Correspondence to: Stacy Ackroyd-Stolarz, stacy.ackroyd@dal.ca

CMAJ 2014. DOI:10.1503 /cmaj.131620 
audit and feedback, ongoing education, skincare champions, and simplification of interventions and documentation. ${ }^{2,9}$ Initiating educational sessions, formalizing processes for auditing documentation, and providing feedback on rates of pressure ulcers to specific services and provider groups at the unit or hospital level may provide sufficient incentives for some practice changes. Other jurisdictions have gone further.

In the US, financial incentives have been introduced by the Centers for Medicare and Medicaid Services through nonpayment policies for preventable, hospital-acquired adverse events such as severe pressure ulcers. ${ }^{9,11}$ The policies have resulted in an unprecedented focus on the detection of pressure ulcers. The underlying premise for these policies is the view that pressure ulcers are considered a medical error because of their potential preventability. Notably, from a population-based perspective in the US, pressure ulcers have been ranked as the most expensive type of medical error. ${ }^{7}$ The policies of the Centers for Medicare and Medicaid Services require that physicians pay careful attention to diagnostic documentation, especially for pressure ulcers present on admission. Deficiencies in documentation may threaten quality of care and patient safety and may result in a shift of legal and financial responsibilities to the provider. ${ }^{11}$ Although the US policies do not affect Canadian hospitals directly, physicians in Canada can provide valuable insights into the use of these payfor-performance models in the Canadian context and provide leadership in promoting an organizational culture of quality and safety.

In addition to effective leadership, an essential ingredient for strengthening system-level prevention efforts is ongoing monitoring. ${ }^{2,9}$ Typically, easily accessible information on pressure ulcers at the hospital level is limited. Routinely collected administrative data such as the data in the Discharge Abstract Database can provide a more efficient option for monitoring the occurrence of pressure ulcers, but the accuracy of the data depends on the quality of documentation in the health record. National coding standards require a documented diagnosis by a physician of a pressure ulcer to code it as such in administrative data. However, physician documentation of pressure ulcers has been shown to be inconsistent. One Icelandic study found that only $4 \%$ of identified pressure ulcers included diagnostic docu- mentation by physicians in the patients' health records. ${ }^{12}$

We are constantly confronted with highly complex problems and issues that defy simple answers. Although the prevention of pressure ulcers is far from simple, practical actions can be taken. One reasonably straightforward action is for physicians to routinely document diagnostic information about pressure ulcers in patients' health records to improve monitoring capabilities. Some physicians may also choose to support or lead system-level efforts to improve quality of care and patient safety by critically examining local practices or by informing policy development on issues such as public reporting and pay for performance. ${ }^{2.9}$ There are many competing priorities each day, but with the current state of our health care system, every action for change aimed at conserving health care resources must be considered.

\section{References}

1. Levert S. Sustainability of the Canadian health care system and impact of the 2014 Revision to the Canada Health Transfer. Schaumburg (Ill.): Society of Actuaries; 2013. Available: www.soa.org/Canadian-Health-Care-Sustainability/ (accessed 2014 Jan. 29)

2. Harrison MB, Mackey M, Friedberg E. Pressure ulcer monitoring: a process of evidence-based practice, quality and research. Jt Comm J Qual Patient Saf 2008;34:355-9.

3. Bennett G, Dealey C, Posnett J. The cost of pressure ulcers in the UK. Age Ageing 2004;33:230-5.

4. Blackman J, Walsgrove J, Gunawardena I. A study examining rates of medical staff recognition of pressure ulceration in hospital inpatients. Postgrad Med J 2013;89:258-61.

5. Woodbury MG, Houghton PE. The extent of chronic wounds in Canada: what we know and what we don't know. Wound Care Canada 2005;3:18-21.

6. Reddy M, Gill SS, Rochon PA. Preventing pressure ulcers: a systematic review. JAMA 2006;296:974-84.

7. Shreve J, Van Den Bos J, Gray T, et al. The economic measurement of medical errors. Schaumburg (Ill.): Society of Actuaries; 2010. Available: www.soa.org/research/research-projects /health/research-econ-measurement.aspx (accessed 2014 Jan. 29).

8. Chan B, Ieraci L, Mitsakakis N, et al. Net costs of hospitalacquired and pre-admission PUs among older people hospitalized in Ontario. $J$ Wound Care 2013;22:341-2, 344-6.

9. Sullivan N, Schoelles KM. Preventing in-facility pressure ulcers as a patient safety strategy: a systematic review. Ann Intern Med 2013;158:410-6

10. Redelings MD, Lee NE, Sorvillo F. Pressure ulcers: More lethal than we thought? Adv Skin Wound Care 2005;18:367-72.

11. Armstrong DG, Ayello EA, Capitulo KL, et al. New opportunities to improve pressure ulcer prevention and treatment: implications of the CMS inpatient hospital care present on admission indicators/hospital-acquired conditions policy: a consensus paper from the International Expert Wound Care Advisory Panel. Adv Skin Wound Care 2008;21:469-78.

12. Thoroddsen A, Sigurjonsdottir G, Ehnfors M, et al. Accuracy, completeness and comprehensiveness of information on pressure ulcers recorded in the patient record. Scand J Caring Sci 2013; 27:84-91.

Affiliation: Department of Emergency Medicine, Dalhousie University, Halifax, NS 